\title{
A Study on the Educational Strategy of Using Folktales in Kindergarten
}

\author{
Guo Huiyu
}

Xi’an University, Xi’an, Shaanxi Province, 710065

Keywords: Infants; Preschool Education; Folktales

\begin{abstract}
At the kindergarten stage, folktales have important educational value in promoting the health development of children, conducting moral education, promoting children's language development and improving their creativity and aesthetic ability. However, with the social development and the invasion of foreign cultures, children nowadays do not have a deep understanding of traditional folktales and they are gradually paying less attention to traditional folktales. Therefore, it is of great importance to study the specific strategies to implement folktales in infant education.
\end{abstract}

Combining theories and practice, this paper strives to propose scientific and feasible ways and methods to better teach and apply folktales at kindergartens, hoping to provide reference for all early childhood educators.

The Chinese culture has a long history and is full of the wisdom of the Chinese nation. As an important part of Chinese culture, folk tales have been passed down, collected and organized by countless generations. They are the crystallization of the collective wisdom of the working people and an important factor in Chinese culture, nourishing countless Chinese children. Most of the folktales are born from the ordinary life of all ethnic minorities. After thousands of years of word of mouth, they gradually take shape. These moving stories with mythology not only tell us the simplicity of the ancient people, but also show us their indomitable spirit of struggle. These magical and beautiful stories bloom like blooms in our hearts, enriching our spiritual life.

Folk tales can promote language education and help children's language development. 3-6 years old is a crucial period of language development, during which children have a strong ability to imitate and memorize languages. At this time, providing children with excellent folktales can effectively promote the development of their language. ${ }^{[1]}$ The language of folk tales is the crystallization of language, which is concise, simple and full of rhythm, so it is conducive to stimulating children's interest in learning national language, greatly enhancing their language imagination and expression ability, and greatly expanding the expression space of language.

Many folk literary works have profound educational significance in content and have strong philosophical significance in life. Through the education of these literary works, children can form a good inner quality, which is a good start for their future study and life. ${ }^{[2]}$ The heroes in the story can often be role models for children to imitate. Teachers should grasp the educational value orientation in each folktale, combine children's daily life with the daily education of children, and skillfully use the "immersion" method to cultivate children's "small habits" so as to lay a foundation for the formation of good moral cultivation, such as courage, persistence, diligence and kindness. ${ }^{[3]}$

Folk stories are conducive to the inheritance of national culture and the cultivation of children's local feelings. There are many works in folk tales that reflect ethnic customs and national character. Young children can feel people's pursuit and yearning for good life. There are many works in traditional folk tales that explain clothing, food, housing, and festival activities. These customs and beliefs enrich the plot and historical and cultural connotations of the story. We can use the story as a carrier to let young children know the local customs and historical background and stimulate the feelings of loving the native land.

Folktales often transcend time and space with twisted and bizarre stories. They are often fantastic, creating a mysterious adventure atmosphere, which is conducive to children's imagination, aesthetic ability and creative spirit. Folktales are magical, fantastic and mysterious, which is in line with the 
characteristics of children's physical development. Folktales are attractive and appealing to children and can arouse children's curiosity. They provide children with a beautiful space for free imagination, and they are in line with children's mental development rules and can stimulate children's will to study independently. ${ }^{[4]}$

The "Working Regulations for Kindergartens" clearly stipulates that one of the main targets to teaching children is to "stimulate their love for their home country, the nation, the collective and work" and "stimulate children's feeling of beauty and expression of beauty". ${ }^{5]}$ The newly issued "Guidelines for Kindergarten Education" also requires us to "make full use of social resources and guide children to actually feel the rich and excellent culture of the motherland", "appropriately introduce the culture of various ethnic groups in China to make children feel the diversity and difference of human cultures, and cultivate their attitude of understanding, respect and equality.",[6] Telling folktales for children is the most basic way. As long as teachers are familiar with and can tell folktales, they can subtly educate children in daily life. ${ }^{[7]}$

However, the author found through investigation that few teachers are familiar with and able to completely tell folktales. $67.3 \%$ teachers can only completely tell 3-4 folktales, $2.3 \%$ teachers cannot event tell a complete folktale, and as many as $90 \%$ teachers can master no more than ten folktales. As far as the value of folk tales is concerned, only $28.9 \%$ of teachers believe that folk tales have obvious value for children's cognitive development, living habits and healthy personality cultivation. The content of some folk tales has a clear historical gap with today's real life. Whether it is the expression of certain words in life at the time, or the life events in the story at the time, they can be hardly understood by children. Most teachers only use folk tales in the language fields of the five major fields, and most of them are conducted in the form of storytelling and performance. With single forms, it is difficult to attract children's interest.

This requires teachers to flexibly process folk stories, select appropriate themes for teaching, and carry out educational activities, so that folk stories can be better applied and developed at kindergartens. The author proposes suggestions to use folk stories in kindergartens:

\section{Exploring the practical part of the folk story that is conducive to the growth of children}

According to children's physical and mental characteristics, aesthetic cognition, emotional attitudes and ability literacy, we choose positive, healthy, simple and understandable stories that are close to children's life while integrating fun, knowledge and aesthetics (including language beauty, image beauty, rhythm beauty and emotional beauty, etc.) from a large amount of folktales. ${ }^{[8]}$ Children at the primary class are too young with poor understanding ability, so simple and appealing contents with vivid language should be chosen for them. Children at the intermediate and upper class have gradually enhanced cognition and understanding ability, so we should choose contents that are closely related to children's life to arouse their resonance and corresponding feelings and stimulate their interest in learning.

Education is an important element in choosing the content of folk tales. The selection of works is based on two considerations: one is the education of love. For example, "Kong Rong Gives up the Bigger Pear" and "Mulan Joins the Army" make children learn the characters in the story and become good boys who love parents, the elderly, teachers, partners, the collective and the motherland. The second is the moral education. For example, "the Wolf Comes" and "The Foolish Old Man Who Removed the Mountains" are humorous and make children understand a lot of truths, such as integrity, courage, honesty, credit and diligence, perseverance, etc., laying a foundation for children's future development.

In the cities we live in, the accumulation of history makes the folk customs of the region full of character. There are also many folk stories that are locally representative and enjoyed by most people, such as "The Legend of the Horse Carrying Sand" and "The Legend of Tang Libao". These local legends can also cause children's strong cognitive resonance, emotional resonance, and stimulate children to know their hometown and love their hometown emotions. ${ }^{[9]}$ 


\section{The folktales should be adapted more interestingly, in line with the needs of children and in a variety of organizational forms.}

Teachers should study and discuss the material of folk stories. In addition to exploring and experimenting in daily teaching activities, teachers should also carry out regular teaching and research activities, adapt traditional stories according to the periodical teaching or age characteristics, organize teachers to create and discuss theme environment, conduct collective preparations, play the creative spirit and explore the means to teach folktales that are suitable for children.

In the adaptation of stories, we need to delete the tedious and repetitive parts according to children's aesthetic ability, expand the character description, add details, enrich the character image to make the story more vivid and interesting. Through the delicate portrayal of the characters' demeanor, children can have a more intuitive feelings and experience so that the value of folktales can be better played. When the story is told, the language is more concrete, shallow, visual, and interesting. We can't just see the knowledge and education contained in the story, but ignore the characteristics of children's psychological laws. We must use the children's interests as the basic starting point to adapt and create. And the story should not be too long, and children can only concentrate for limited time. Over a long time, children will lose the interest, and their attention can be distracted, so that good resources can become burden.

Take a variety of organizational forms: (1) parent-child sharing. Invite parents to collect folk stories and related materials to participate in the event. Ask young children to serve as small reporters and interview parents or grandparents about their folk stories in their memory. They can also collect some folk stories through the Internet and reading books. With the joint efforts of parents and children, some forgotten folktales will be re-returned, increasing children's interest in folktales. (2) Permeability activities. Permeability education activities refer to educational activities in the environment and in the daily life of young children. ${ }^{[10]}$ Children's ability is gradually accumulated and developed through a long-term and repeated process. With the resources of traditional folktales, we can create more opportunities for young children to achieve greater development of multiple intelligences. For example, creating corner activities in daily life, in informal activities and in the interaction with the environment; (3) specialized display activities. In response to the nature of children's love performances, special performances can be held every semester, such as the folktale family small theater. Every family can freely choose folk tales, make up props and costumes, and assign characters according to the folktale plot. Fathers, mothers and children must play their respective roles and perform.

\section{Establish a "folk story resource library" at kindergarten to promote the development of children's folktale education}

In the implementation of the folktale theme activities, many of the headwear, headgear, costumes, props, decorative paper art and other physical objects can also be arranged in the "thematic resource library" of the kindergarten. This will create a large database for all parents and educators in need. For example, in the process of teaching folk songs to young children, when telling the traditional folk stories of ethnic minorities, teachers can use rich and varied national costumes to let children feel the styles of different nationalities and make full use of national costumes to make children understand. When talking about the folktales of the Yi people, the children's national costumes can be introduced to the children's regional characteristics, customs, customs, national ideology, etc., so that children have more interest in and understand Yi costumes and culture and art so that young children can clearly understand the story.

Kindergartens should carry out the construction of the "Folk Story Library". For example: collecting and screening excellent folk stories suitable for young children; making and collecting folktale teaching videos; organizing folk story teaching activity songs; making folk story teaching PPT; collecting folk stories related pictures, etc. Kindergartens can also purchase folk story image resources produced by modern information means in publishing and film. These materials use video 
editing software design and produce "folk story video courseware", and pictures, animation, music and other elements that children are interested in to present the contents of folktales. Excellent teachers can use folktales drama to perform videos and arrange information resource libraries. This multimedia means can fully mobilize and cultivate children's perception of languages.

Folk tales are not only a story, but also a spiritual existence, a lively history. Therefore, combining folktales and early childhood education to promote the growth of young children in practice has unique and far-reaching significance for the healthy development of children and cultural inheritance.

At present, although many people have begun to pay attention to national folk culture, the proportion of national culture chosen for early childhood education is far from enough. In view of this, it is an unshirkable responsibility and task for current preschool educators to explore excellent national cultures that are more suitable for young children and to supplement them as early childhood education courses. For early childhood educators, creating a healthy cultural environment for children and making them thrive is an unshirkable responsibility and task.

\section{References}

[1] Xu Zhuoya. The Psychological Exploration of Learning and Teaching [M]. Nanjing; Nanjing Normal University Press, August 2006: 10-14

[2] Zheng Jiancheng, editor. Preschool Education [M] Fudan University Press, March 2012: 89

[3] Li Cuilan.The Influence of Children's Literature on the Development of Children's Feelings [J] Pupils’ Composition Counseling: Teacher Application, 2012 Xi, May 2013: 2

[4] Zhu Jing. Feeling the Charm of Folk Stories [J] Early Childhood Teaching Research, February 2006: 1

[5] Ministry of Education. Procedural Work Rules for Kindergartens. Teaching Base, March 9, 1996

[6] Ministry of Education. Guidelines for the Guidance of Kindergarten Education (Trial). Teaching Base [2001120].

[7] Xu Xiaoying. Service Growth: Folk Story into Kindergarten [J], April 2017: 1

[8] Lan Jing. Using Folk Literature Education and Cultivating Children's Emotional Consciousness [J] Modern Marketing, April 2012: 3

[9] The Life of Course Content Research [J] Preschool Curriculum Research, October 2009: 2

[10] Wu Yingqin. On the Role of Teachers in Folk Literature Activities [J] New Curriculum: 1 